\title{
Demographic and Social Factors associated with HIV discordance among HIV-infected couples in Kaduna State Nigeria.
}

Daniel Abba Danboyi ( $\sim$ daniel_abba@yahoo.com )

Kaduna State College of Nursing and Midwifery Kafanchan.

\section{Research Article}

Keywords: Human Immunodeficiency Virus (HIV), Local Government Areas (LGAs), Antiretroviral therapy (ART), Discordance

Posted Date: March 9th, 2022

DOI: https://doi.org/10.21203/rs.3.rs-1292944/v2

License: (c) (i) This work is licensed under a Creative Commons Attribution 4.0 International License.

Read Full License 


\section{Abstract}

Background: Discordance has always been a bane in the efforts to stop the spread of HIV within the population as it creates a gap through which re-infection occurs. Knowing the demographics associated with discordance will help in the fight against HIV AIDS transmission.

Objectives: The study was conducted to assess the demographic and social factors associated with HIV discordance among HIV- infected couples.

Methods: A total of 158 couples and 317 individuals were recruited for the survey using a stratified sampling technique. A detailed closed-ended questionnaire was administered to them to collect their demographic and social information. A blood test was also carried out to confirm their HIV status.

Results: The majority $161(50.8 \%)$ of respondents had secondary education while the least $29(9.1 \%)$ of them had tertiary education. Most of the 135(42.6\%) knew their HIV status by voluntary testing, and most respondents 255(71\%) were Christians while only 92(29\%) were Muslims. More women 105(66.04\%) were HIV positive, and the HIV discordance prevalence for Kaduna State was $0.2 \%$. Social factors such as education, employment, unprotected sex, extramarital affairs, body marks/tattoo, surgery/operation, tribal marks, and blood transfusion did not affect HIV discordance, p-value $\otimes 0.05$. Other social factors such as remarriage, use of antiretroviral therapy (ART), pre-marital sex, male/female circumcision, and polygamy were found to affect HIV discordance, $p$-value $\otimes 0.05$.

Conclusions: There is a need to draw the attention of HIV-infected couples to these facts to succeed in the global war against HIV AIDS.

\section{Introduction}

Discordance among HIV-infected couples is a common phenomenon in sub-Saharan Africa and this has always been a challenge in the struggle for HIV prevention and cure. ${ }^{1,2}$ Discordant couples are those where one partner is HIV-infected while the other is not, where a couple is defined as two persons in an ongoing sexual relationship and each of these persons is referred to as a "partner" in the relationship.,4 There are two types of discordance: hard and soft. Hard discordance is when the male partner is HIV positive while soft discordance is when the female partner is HIV positive. ${ }^{4}$ In another report, Merenu et al. ${ }^{5}$ also mentioned that serodiscordance can be called magnetic or mixed-status. Discordance usually results from initial non-disclosure before marriage or relationship, traditional marriages without premarital counseling and testing, latency in the event of infection before marriage, and accidental infection of a partner during a marriage or sexual relationship. ${ }^{6}$

The phenomenon of discordance among HIV-infected couples has remained a mirage and a concept that needs to be unraveled. It has remained so for as long as when the discovery of the mutant alleles of the CCR5 gene came to the fore. ${ }^{7,8}$ The mutant allele concept is just one possibility; there could be other reasons such as reduced viraemia or innate resistance. Knowing that majority of HIV-1 infection which 
occurs in Africa is among individuals in stable sexual partnership, improving our understanding of the correlates of discordance will provide information on the dynamics and risk factors of couple transmission that can assist in the development of interventions to reduce transmission within couple relationships. HIV discordant partnerships can constitute core risk groups for the transmission of HIV infection. ${ }^{9}$ Gray et al. ${ }^{10}$ also reported that HIV-negative members of discordant partnerships are at extremely high risk of infection, with the annual incidence of 10 to 100 fold higher than that of their HIV concordant negative counterparts.

\section{Materials And Methods}

\section{Study area/population}

A total of 158 couples or 317 persons who are either HIV positive or negative from 9 LGAs of the 23 LGAs of Kaduna State, Nigeria were recruited for the study using a stratified sampling technique. Kaduna State is one of the 19 northern states of Nigeria and has long been seen as the Major capital of the northern region, and now the capital of the North West. It is ranked $4^{\text {th }}$ by land area and $3^{\text {rd }}$ by population in Nigeria. The state capital was the former capital city of the British protectorate of the Northern Nigeria region (1923-1966) after Zungeru (1903-1923) and Lokoja (1897-1903). It is made up of some major towns which include: Zaria, Kagoro, Kafanchan, Kachia, Zonkwa, Makarfi, and Birnin Gwari. ${ }^{11}$ Kaduna State has coordinates of $10^{0} 20^{\prime} \mathrm{N} 7^{0} 45^{\prime} \mathrm{E}$ of Nigeria. It has a total land area of $46,053 \mathrm{~km}^{2}$ and a total population of $6,113,503$ according to the 2006 population census of Nigeria. ${ }^{12}$ Kaduna State has over 1,000 primary healthcare facilities to cater to every resident - even in the most remote village or ward of the state. In addition to these, the government has made efforts to establish General hospitals in each of the 23 LGA headquarters to enhance effective and accessible healthcare for its citizens. These General hospitals have now become treatment centers for HIV anti-retroviral therapy all around the state.

A structured questionnaire was administered to capture demographic data (sex, educational qualification, religion, marital status, and employment status) of respondents; and social factors (discovery of HIV status, unprotected sex, use of ARTs, use of condom, pre/ extramarital affairs, polygamy, male/ female genital mutilation, tattoo/ surgery and tribal marks, blood transfusion) of respondents. Blood samples were also collected from HIV-negative partners to re-screen the clients for their HIV status. This was done in a space of 4months, from July 2020 to November 2020.

\section{Sample collection}

The questionnaire was issued to the HIV-positive partners at the treatment center on clinic days after proper enlightenment on the essence of the study. Five milliliters $(5 \mathrm{ml})$ of whole blood was aseptically collected from the cephalic vein of the ante-cubital fossa of each HIV-negative donor after signing informed consent at the end of the group information session (GIS). A sterile EDTA container was used to keep the whole blood unclotted and stored in the refrigerator for further analysis. 


\section{Test procedure (HIV serology)}

The test device (cassette) was removed from the foil and placed on a flat surface (laboratory worktop). A blood sample (about $20 \mu \mathrm{L}$ ) was dropped onto the testing reagent Determine. UNI- GOLD was later used for a confirmatory test. Any sample that yielded discordant results in two tests was resolved using STATPAK as the tie-breaker. This followed the national guidelines for a rapid test as outlined by UNAIDS/WHO, 2004 using serial algorithm. ${ }^{13}$

\section{Statistical analysis}

The data generated in this study were analyzed for statistical significance in the association of HIV discordance and demographic social factors using Pearson Chi-square, Fisher's exact test with the aid of statistical package for social sciences (SPSS) version 21. The significance level was set at a $p$-value of $\leq$ 0.05 .

\section{Results}

\section{Demography}

One of the inclusion criteria in this study was that participants must be couples who have been in stable sexual activities for at least one 1year. For this reason, sex is of no significance here- they must be male and female but however, one man had two wives in participation- this is why we had 317 respondents for 158 couples. Similarly, age is of no significance here because all participants were adults (18years and above) to participate. Table 1 shows that the majority of $161(50.8 \%)$ of respondents, had secondary education followed by $72(22.7 \%)$ who had primary education. Those who had no education were $55(17.4 \%)$ while those with tertiary education were only $29(9.1 \%)$.

\section{Table 1: Demographic Factors Associated with HIV Discordance in Kaduna State $(\mathrm{N}=317)$}




\begin{tabular}{|c|c|c|}
\hline Characteristics & Frequency(\%) & P-Value \\
\hline \multicolumn{3}{|c|}{ Education } \\
\hline No Formal education & $55(17.4)$ & 0.29 \\
\hline Primary & $72(22.7)$ & \\
\hline Secondary & $161(50.8)$ & \\
\hline Tertiary & $29(9.1)$ & \\
\hline Total & $317(100)$ & \\
\hline \multicolumn{3}{|c|}{ Knowledge of HIV status } \\
\hline Illness/ Hospital treatment & $68(21.5)$ & 0.97 \\
\hline Awareness & $43(13.6)$ & \\
\hline Voluntary testing & $135(42.6)$ & \\
\hline ANC & $71(22.4)$ & \\
\hline Total & 317100) & \\
\hline \multicolumn{3}{|c|}{ Religion } \\
\hline Christianity & $225(71.0)$ & 0.97 \\
\hline Islam & $92(29.0)$ & \\
\hline Total & $317(100)$ & \\
\hline \multicolumn{3}{|c|}{ Gender } \\
\hline Male & 158(49.8) & 0.00 \\
\hline Female & $159(50.2)$ & \\
\hline Total & $317(100)$ & \\
\hline
\end{tabular}

Chi-square P-Value

If we look at how they got to know about their HIV status, we will realize that in Table 1, a large number 135(42.6\%) went on their own to test for HIV in both men and women. Pregnant women who were in antenatal clinic 71(22.4\%) were tracked down and tested. Another 68(21.5\%) were tested while in hospital treatment against their wish but to help the doctor achieve an effective and well-informed therapeutic diagnosis. The last group was 43(13.6\%) individuals who through one of the HIV enlightenment awareness campaigns agreed to be tested. Also in Table 1, the results show that more Christians $225(71 \%)$ participated in the study than the Muslims $92(29 \%)$. Finally, Table 1 also revealed that there is a significant relationship between sex or gender and HIV discordance as the Chi-square p-value is 0.00 , far below the 0.05 confidence limit. The results shown in Table 2 indicate that most of the factors: Religion, Education, Employment, Unprotected sex, Extramarital affairs, Tattoo, Surgery, Tribal marks, and Blood transfusion do not have any association with HIV discordance among couples. However, on the other hand, factors such as Remarriage, use of antiretroviral drugs (ART), premarital sex, polygamy, and male/female circumcision can cause HIV discordance among couples. 
Table 2: Social Factors Associated with HIV Discordance $(\mathrm{N}=317)$

\begin{tabular}{lccc} 
Factor & Yes (\%) & No ( \% ) & P-Value \\
\hline Education & $262(82.6)$ & $55(17.4)$ & 0.29 \\
Employment & $49(15.5)$ & $224(70.1)$ & 0.40 \\
\hline Remarriage & $72(22.7)$ & $245(77.3)$ & $0.01^{*}$ \\
\hline Unprotected Sex & $296(93.4)$ & $21(6.6)$ & 0.49 \\
\hline ART & $157(49.5)$ & $160(50.5)$ & $0.00^{*}$ \\
\hline Premarital Sex & $147(46.6)$ & $170(53.6)$ & $0.00^{*}$ \\
\hline Extramarital Affairs & $46(14.5)$ & $271(85.5)$ & 0.54 \\
\hline Polygamy & $35(11.0)$ & $124(39.1)$ & $0.00^{*}$ \\
\hline Body Marks/ Tattoo & $20(6.3)$ & $297(93.7)$ & 0.63 \\
\hline Surgery/ Operation & $51(16.1)$ & $266(83.9)$ & 0.46 \\
\hline Tribal Marks & $137(43.2)$ & $180(56.8)$ & 0.13 \\
\hline Male/ Female Circumcision & $165(52.1)$ & $152(47.9)$ & $0.00^{*}$ \\
\hline Blood Transfusion & $55(17.4)$ & $262(82.6)$ & 0.44 \\
\hline Religion & Christianity & Islam & \\
\hline & $225(71.0)$ & $92(29.0)$ & 0.97 \\
\hline
\end{tabular}

* Statistically Significant Factor

Figure 1 shows a higher incidence of HIV infection among women partners 105(66.04\%) than the men 53(33.54\%) in Kaduna State.

\begin{tabular}{ccc}
\multicolumn{3}{c}{ Table 3: Incidence of HIV Discordance in Kaduna State $(\mathbf{N}=\mathbf{3 1 7})$} \\
\hline Item & Number of People & Percentage (\%) \\
\hline Total Population & $6,115,503$ & 100 \\
\hline HIV Prevalence & 67,271 & 1.1 \\
\hline HIV Sero- discordance & 158 & 0.2 \\
\hline
\end{tabular}

Table 3 shows a state discordance prevalence of $0.2 \%$ as calculated from a United Nations national report of 2019 which places Kaduna on a state HIV prevalence of $1.1 \%$.

\section{Discussion}

The study revealed in Table 1, that most of the population 161(50.8\%) had secondary education while the lowest size of the population $29(9.1 \%)$ had acquired tertiary education. If we relate this to Kaduna State, 
we could conclude that the results gave a reflection of the educational coverage of the state. This means about $51 \%$ of Kaduna State people had secondary education while only about $9 \%$ had tertiary education. $72(22.7 \%)$ of respondents had primary education while $55(17.4 \%)$ had no education at all. Similarly, we can say that $22.7 \%$ of Kaduna State people had primary education while $17.4 \%$ were not literate at all.135(42.6\%) of respondents got to know of their HIV status by voluntary testing, while 71(22.4\%) were pregnant women who got tested while on antenatal care (ANC) clinics. Even though awareness has only $43(13.6 \%)$, when we sum it up with voluntary testing, the result $178(56.2 \%)$ gives a huge success rate for the global campaign on voluntary counseling and testing in Kaduna State. This also agrees with the WHO guidelines on HIV counseling and testing services. ${ }^{14}$ Table 1 also revealed that more Christians 225(71\%) participated in the study than Muslims $92(29 \%)$. This result also points to the fact that in treatment centers more Christians were seen participating- even in Muslim- dominated areas. This is because of stigmatization; people moved far away from their localities to access treatment in strange lands where the chances of identification were very slim. This agrees with the reports of Earnshaw and Kalichman ${ }^{15}$ and Saki et al. ${ }^{16}$ Figure 1 shows the distribution of respondents based on their HIV status. The results show that more men 105(66.46\%) were HIV negative while more women 105(66.04\%) were HIV positive. This really agrees with what we see in the communities- more women are positive than men; and this goes in line with the report of Magaji et al. ${ }^{17}$ Biologically, women are two to eight times more likely than men to contract HIV during vaginal intercourse ${ }^{18,19}$ and obviously, our results agree with such findings. We can also conclude that a large proportion of HIV discordance in Kaduna State is "soft discordance". 20 On the other hand, the results in Figure 1 do not agree with one particular report which found out that more men were HIV positive among discordant couples in Anambra State, Nigeria. ${ }^{20}$ The results in Table 2 showed us an array of social factors that were associated with HIV discordance. ${ }^{21}$ Chi-square tests for these factors showed that for p-value $\mathbb{0 . 0 5}$ : only remarriage, use of ART, pre-marital sex, polygamy, and male/female circumcision affected HIV discordance. But this result did not agree with an earlier report ${ }^{22}$ which stated that ARV/ART does not have a significant difference with discordance. Other factors such as religion, education, employment, unprotected sex, extramarital affairs, body marks/tattoo, surgery/operation, and tribal marks do not affect HIV discordance; this seems to disagree with Akani et al. ${ }^{23}$ who reported that extramarital affair is a factor that predisposes to HIV sero- discordance. So, it can be deduced that based on this study, factors that predispose to HIV discordance are: REMARRIAGE, USE OF ART, PRE- MARITAL SEX, POLYGAMY, and MALE/FEMALE CIRCUMCISION. Table 3 results showed that Kaduna State HIV prevalence was $1.1 \%$, from which HIV discordance prevalence was calculated to be $0.2 \%$. This agrees with Magaji et al. ${ }^{17}$ who reported low sero- discordance in Plateau State Nigeria.

\section{Conclusion}

In this study, we observed that about $17.4 \%$ of people in Kaduna State were not literate while $51 \%$ of the population had secondary education. The results of "how respondents got to know about their HIV status" revealed to us a $56.2 \%$ success rate for voluntary counseling and testing (VCT) in Kaduna State, Nigeria. Also, we discovered as always that more women $66.04 \%$ were HIV positive than men in the population- 
the major reason being their biological make-up. The prevalence of discordance in Kaduna State was also seen to be, low at $0.2 \%$. Furthermore, factors that predispose to HIV discordance include male/female circumcision, use of ART, remarriage, premarital sex, and polygamy.

\section{List Of Abbreviations}

HIV, AIDS, ANC, ART, ARV, VCT, LGA.

\section{Declarations}

\section{Compliance with Ethical Standards:}

Ethics approval and consent to participate- The study was conducted according to ethical standards for human studies as approved by the research and ethics review committee of the Kaduna State Ministry of Health, and Human Services. MOH/ADM/744/VOL.1/913. See document here https://drive.google.com/file/d/1_Jnlr30XLQWQVNwVoAZLWY39x2cbg-mB/view?usp=sharing

Informed consent was obtained from all participants to take part in the study, after adequate explanations on the purpose, risk, method, and benefit of the research. LINK https://drive.google.com/file/d/1_uWS7jP01VAPzbf6pmtGcm61afmWKUc6/view?usp=sharing Consent for Publication- Consent was received from participants. See LINK https://drive.google.com/file/d/1eVGYJ7F-QOuDfrfiN7o9B10PjPHvrOBs/view?usp=sharing

Kaduna State Map is available here

https://drive.google.com/file/d/1eyNtIG3tVZLDOazH8nA88IpbhzWwi7_L/view?usp=sharing

Declaration - No funding was received for conducting this study.

Competing interests- None declared

\section{Authors' contributions}

Danboyi DA conceived the study and participated in its design and coordination.

Sani MN and Danboyi DA conducted the statistical analysis.

Danjuma $\mathrm{L}$ and Abdullahi $\mathrm{M}$ handled the study review.

\section{ACKNOWLEDGEMENTS}


The authors wish to appreciate the support of the Kaduna State ministry of health for making their facilities and staff available for this study. The Clients who visited these treatment centers to access antiretroviral treatment are also recognized for their cooperation.

\section{References}

1. Matovu JK. Preventing HIV transmission in married and cohabiting HIV-

Discordant couples in sub- Saharan Africa through combination prevention. Curr HIV Res 2010;8(6):430440. doi: $10.2174 / 157016210793499303$.

2. Curran K, Baeten J, Coates T, Kurth A, Mugo N, Celum C. HIV- 1 Prevention for HIV- 1 serodiscordant couples. Curr HIV/AIDS rep 2012;9:160- 170. doi: 10.1007/s11904-012-0114-z.

3. Mazzota M. WHO issues new guidelines for discordant couples. Science Speaks 2012:

Global ID News. Accessed July 5,2020.http://whqlibdoc.who.int>9789241501972_eng

4. Mehra B, Bhalla P, Rawat D, Kishore J. A study of HIV-concordant and discordant couples attending voluntary counseling and testing services at a tertiary care center in North India. Indian J Public Health 2015;59(4):306-309. DOI: 10.4103/0019-557X.169664

5. Merenu IA, Dikwe KC, Uwakwe KA et al. The prevalence of HIV serodiscordance among couples attending HIV clinics in Imo State, Nigeria. Int J Curr Res 2016;8(4): 29723- 29727. ISSN: 0975- 833X

6. Onovo AA, Nta IE, Onah AA et al. Partner HIV serostatus disclosure and determinants of serodiscordance among prevention of mother to child transmission clients in Nigeria. BMC Public health 2015;15: 827.https://doi.org/ 10.1186/s12889-015-2155-x

7. Diaz FJ, Vega JA, Patino PJ et al. Frequency of CCR5 Delta-32 Mutation in Human 
Immunodeficiency Virus (HIV)-seropositive and HIV-exposed Seronegative Individuals and in General Population of Medellin, Colombia. Mem Ist Oswaldo Cruz 2000;95(2):237- 242.

https://doi.org/10.1590/S0074-02762000000200018

8. Trecarichi EM, Tumbarello M, DonatiK DG et al. Partial protective effect CCR5 D32 heterozygosity in a cohort of heterosexual Italian HIV- 1 exposed uninfected individuals. AIDS ResTher 2006;3(22).Doi 10.1186/1742- 6405- 3- 22

9. NACA. National Agency for Control of AIDS (NACA), \{Nigeria\}, author National Strategic Plan on HIV/AIDS 2009;2010-2015:1-76. Accessed July 10, 2020.

https://www.ilo.org>legaldocument>wcms_146389

10. Gray RH, Wawer MJ, Brookmeyer R et al. Probability of HIV transmission per coital act in monogamous, heterosexual HIV discordant couples in Rakai Uganda. Lancet 2010;357:1149-1153.doi: $10.1016 /$ S0140-6736(00)04331-2.

11. Kaduna State- Explore Nigeria Explorenigeria.com:ng/states/Kaduna-state/ 2020. Retrieved From Wikipedia.

12. NPC. 2006 PHC Priority Tables- NATIONAL POPULATION COMMISSION. population.gov.ng. Achieved from the original on 2017-10-10. Retrieved 202006- 13. https://en.wikipedia,org>wiki>List_of_Nigerian_state

13. FMOH. National guidelines for HIV and AIDS treatment and care in adolescents and adults 2007. Federal Ministry of Health Abuja Nigeria. Accessed June 6,2020. https://www.who.int>amds>Nigeria_adults_2007

14. WHO. Scaling- up HIV testing and counseling services: a toolkit for programme managers 2005. ISBN $924159327 X$ 
15. Earnshaw VA, Kalichman SC. In Liaputtong P. Ed.2012. Stigma experienced

by people living with HIV/AIDS: A Cross- Cultural Perspective. Chapter 2.NewYork, NY: Springer. DOI:10.1007/978-94-007-6324-1_2

16. Saki M, Kermanshahi SM, Mohammadi E, Mohraz M. Perception of patients with HIV/AIDS from stigma and discrimination. Iran Red Crescent Med J 2015;17(6):e23638 DOI: 10.5812/ircmj.23638v2

17. Magaji FA, Ocheche AN, Pam VC et al. HIV status in sero- discordant couples:

Prevalence and Pattern among pregnant women in Plateau State, Nigeria. J Clinical Res HIV AIDS Prev 2018;3(2):33- 40. DOI 10.14302/issn.2324-7339.jcrhap-18-2236

18. Cummins JE, Dezzutti CS. Sexual HIV-1 Transmission and Mucosal Defense Mechanisms. AIDS Review 2000;2:144-154, cited by amfAR, The Foundation for AIDS Research, Fact Sheet: Woman and HIV/AIDS. March 2008. Accessed June 10, 2020. https://iwhc.org>wp-content>uploads>2016/10

19. IPPF/UNFPA. Young Positives, Change, Choice and Power: Young Women, Livelihoods and HIV Prevention 2007. Accessed July 5, 2020. https://www.unfpa.org>sites>files>resource-pdf

20. Nnebue C, Anaekwe A, Anaekwe C. Sociodemographic Correlates of HIV discordant and Concordant couples in Anambra State, Nigeria. Ethiop J Health Sci. 2017;27(4):363-372.doi: 10.4314/ejhs.v27i4.7

21. Tadesse M. Assessment of HIV discordance and associated risk factors among Couples receiving HIV test in Dilla, Ethiopia. BMC Research Notes 2014;7:

893. https://doi.org/ 10.1186/1756-0500-7-893 
22. Afe AJ, Fadero T, Oluokun O. HIV Sero-Discordant Couples in Southwest Nigeria: Prevalence and Associated Risk Factors. J Aids Hiv infec 2015;1(1):103.doi: 10.15744/2454-499X.1.103

23. Akani CL, Erhabor O, Opurum H, Ejele OA, Nwauche CA. HIV sero-Discordance among Nigerian couples: challenges and controversies. Nigerian Medical Practitioner 2005;48(3):62-66. DOI: 10.4314/nmp.v48i3.28766

\section{Figures}

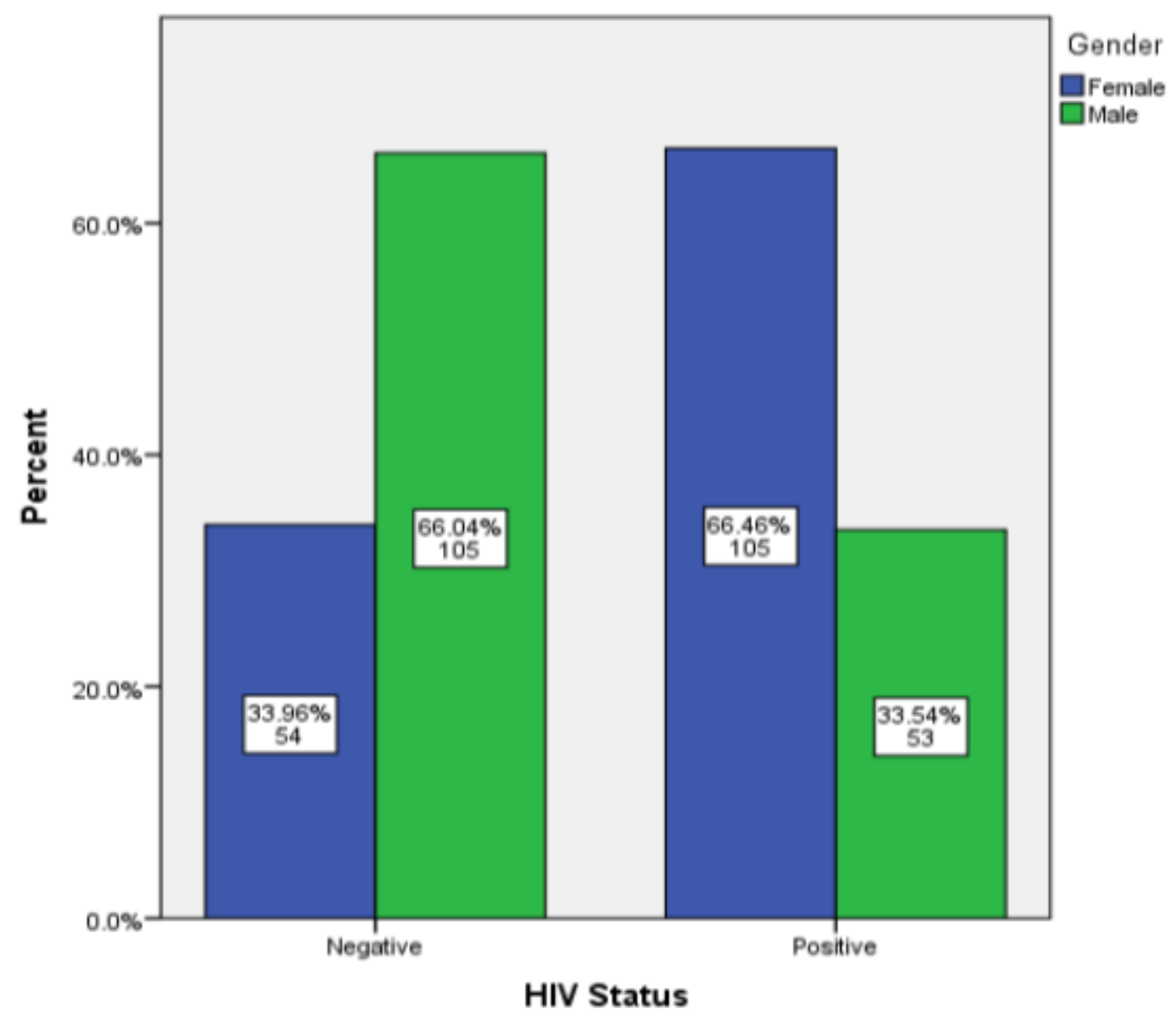

Figure 1

HIV Status of Respondents $(\mathrm{N}=317)$ 